\title{
Perception on Psychiatric Reform from A Standpoint of the Families
}

\author{
Bruno Vilas Boas Dias ${ }^{1 *}$, Érica Alves da Conceição² and Laís Fecchio Garcia² \\ ${ }^{1}$ Master in Health Sciences, Campo Limpo Paulista University, Brazil \\ ${ }^{2}$ University Center Padre Anchieta in Jundiaí, Brazil
}

*Corresponding author: Bruno Vilas Boas Dias, Master's in health sciences, Professor of Padre Anchieta University in Jundiaí and Campo Limpo Paulista University, Brazil

To Cite This Article: Bruno Vilas Boas Dias. Perception on Psychiatric Reform from A Standpoint of the Families. Am J Biomed Sci \& Res. 2019 3(6). AJBSR.MS.ID.000729. DOI: 10.34297/AJBSR.2019.03.000729

Received: June 03, 2019 | Published: July 10, 2019

\begin{abstract}
The aim of this study was to obtain the perception of the relatives of patients with mental disorders, about the treatment offered at the Psychosocial Care Center (CAPS) and to identify the preference about the hospitalization in psychiatric hospitals and the treatment offered after the Psychiatric Reform. Qualitative, descriptive and exploratory research based on the Theory of Social Representations, following the guidelines of the Discourse of the Collective Subject. The sample consisted of 20 relatives of patients who were treated at CAPS II, in the city of Campo Limpo Paulista, in the interior of São Paulo. The central ideas obtained by relatives who are in favor of hospitalization in psychiatric hospitals were: "Aggression" and "Benefit of Hospitalization". Family members who are not in favor of hospitalization and prefer the treatment offered by CAPS were: "Ineffective Method of Hospitalization" and "Family Tie ". Even after the Psychiatric Reform, there are still relatives in favor of hospitalization in psychiatric hospitals.
\end{abstract}

Keywords: Mental Health; Family; Psychiatric Nursing

\section{Introduction}

In the Middle Ages, patients with mental illness were imprisoned in nursing homes and hospitals, where they were among patients with vulnerable diseases, invalids, criminals, beggars among others. Many of them were chained and others were only allowed to go out to beg [1].

In the eighteenth century the physician and Frenchman Phellippe Pinel, was considered the pioneer in the treatment of patients with mental illness, banned several treatments that were used at the time and instituted others considered more dignified and respectful, including occupational therapy, besides separating mental patients from criminals and put them under medical care [2].

From the nineteenth century, the treatment instituted by Pinel was modified and distanced from the original idea, returning the treatment to physical measures such as lashes, cold baths, spinning machines and sangrias. The Italian psychiatrist Franco Basaglia was the forerunner of the Italian Psychiatric Reform in the middle of the XX century, where repercussions were obtained all over the world [1].

In 1970 Basaglia was appointed director of the Provincial Hospital of the city of Trieste in Italy, thus initiating the process of clos ing the psychiatric hospital, promoting the replacement of hospital and manicomial treatments by a territorial network of care, resulting in the movement of the Antimanicomial Struggle.

The World Health Organization (WHO) accredited the reformulation of psychiatric treatment in 1973, which was instituted by Basaglia [3].

Associated with Antimanicomial Struggle, the Psychiatric Reform movement was born, in which it came with a proposal to build a network of territorial and community services, strategies, inclusive and libertarian, deeply in solidarity. In Brazil, due to the mobilization of family members of patients with mental illnesses and health professionals, the Psychiatric Reform movement began in the late 1970 [1].

The Psychiatric Reform with the purpose of implementing changes in the hospitalization of patients with mental disorders had a great repercussion, to the point of appearing in favor of the movement called Mental Health Workers' Movement (MHWM), which were against hospitalization and poor conditions in which the patients were submitted $[4,5]$.

The main purpose of the reform is to integrate the subject into society, thus creating the Psychosocial Care Center (PCC), which is 
characterized as a reference in the treatment of people with mental disorders, in order to follow up and reinsert that individual in society $[4,6]$.

The first PCC was created in São Paulo in the year 1986, called the Psychosocial Attention Center Professor Luiz da Rocha Cerqueira. The ordinance GM 336/02 regulates the creation of the PCC, where it is divided into five categories:

a. PCC I: A daily service, with a Monday to Friday operation in municipalities with a population of 20,000 to 70,000 inhabitants;

b. PCC II: Aims at a daily service, running from Monday to Friday in municipalities with a population of 70,000 to 200,000 inhabitants;

c. PCC III: Aims at a 24-hour service in municipalities with a population of more than 200,000 inhabitants;

d. PCC of childcare: Aims at a daily care of children and adolescents, and may also have a third shift (open until 9pm), running from Monday to Friday in municipalities with a population above 200,000 inhabitants;

e. PCCad: Aims to provide a service for alcohol and drug users, daily, and can also have a third shift (open until 9pm), running from Monday to Friday in municipalities with a population above 100,000 inhabitants.

To be attended to in PCC, the person must have some severe or persistent mental disorder. When the individual is referred to the PCC or seeks the unit for their own account, they will first be submitted to a reception, where the professional will understand his case, thus initiating the therapeutic link, which aims to become a reference professional and accompany this patient any period that the same goes through the PCC [7].

The PCC is a system that will address both the individual and his / her family, with the purpose of inserting the family in the practices that will be worked in the institution, thus increasing the affective bond [8].

\section{Methods}

The study followed a qualitative exploratory approach. The sample consisted of 20 family members of patients who were treated at PCC II in the city of Campo Limpo Paulista in the interior of São Paulo, were randomly chosen, through the acceptance of the research participation.

The research was authorized by the PCC and followed all the recommendations of Resolution MS/CNS 466/12. The data collection occurred after approval in the Ethics Committee of the University Center of Campo Limpo Paulista Unifaccamp, registered under the opinion of No. 2,731,349.

The interviews were previously scheduled and performed at the PCC, the treatment site of the patients in July and August of 2018. The answers were transcribed in full.

The family members answered two semi structured questionnaires prepared by the researchers, one, referring to the age, gender, degree of relationship, treatment time, disease time, type of illness and hospitalization in a psychiatric hospital, composed of eight questions; two guiding questions: "For you, how is the treatment offered in PCC II?" And "Are you in favour of the hospitalization of your relative in a psychiatric hospital? Because?".

The option for Collective Subject Discourse (CSD) was the chosen method for the construction of meanings, allowing the approximation with the phenomenon under study.

The CSD consists of the meeting, in a single synthesis speech, of several individual discourses issued as a response to the same research question, by an institutionally equivalent social subject or part of the same organizational culture. According to the guidelines of the CSD, three methodological figures were adopted in this study: Key Words (KW), Central Ideas (CI) and Collective Subject Discourse (CSD).

For the treatment and analysis of the data, the following order was strictly followed [9]. 1st stage: before the beginning of the copy of the data, the answers were read several times to obtain a panoramic idea and a better understanding of the texts. Subsequently, they were copied verbatim, that is, the participants' responses to the Discourse Analysis Tool 1 (DAT1) were copied. In the second stage, all the transcribed material was thoroughly read. In the $3^{\text {rd }}$ step all the answers were analyzed to identify the KWs that were passed to italics. Once the KWs were in possession and after reading each one, the CI was identified for each subject of the study, taking care that it represented the description of KWs and not their interpretation. This same procedure was performed with the other responses until the last one. In the $4^{\text {th }}$ stage, the Discourse Analysis Tool 2 (DAT2) was elaborated, containing, separately, each central idea with its respective similar or complementary KWs.

In Step 5 the theme of each of the interview questions was grouped together with their respective CIs, as well as the participants, establishing the absolute and relative frequencies of ideas, organizing them into a table. At this point, the CSDs were constructed separately from each CI with their respective KW [10].

\section{Results and Discussion}

The present research was carried out with $20(100 \%)$ relatives, among them 7 (35\%) are mothers of the patients, 4 (20\%) wives, 3 (15\%) siblings, $2(10 \%)$ parents, $2(10 \%)$ children, 1 (5\%) spouse and $1(5 \%)$ girlfriend. Regarding the age of the interviewees, 9 (45\%) are 18 to 50 years old and $11(55 \%)$ are 51 to 61 years old or older. The patients, $10(50 \%)$ are 20 to 40 years old and $10(50 \%)$ are 41 to 60 years old.

Regarding the gender of the patients, 14 (70\%) are male and 6 (30\%) are female. As to hospitalization in psychiatric hospitals, 11 (55\%) patients were never hospitalized and 9 (45\%) were hospitalized, 16 (80\%) of whom were diagnosed with schizophrenia, 2 (10\%) alcohol and drug 1 (5\%) depression, 1 (5\%) panic syndrome.

In relation to the time of diagnosis of the disease in $2(10 \%)$ patients was less than 1 year, 9 (45\%) between 1 year to 10 years, $5(25 \%)$ between 11 years to 20 years and 4 (20\% than 20 years. Most patients, 12 (60\%) of whom are in PCC within 1 to 3 years, and $8(40 \%)$ of patients are less than 1 year old (Table 1$)$. 


\begin{tabular}{|c|c|c|}
\hline \multicolumn{3}{|c|}{$\begin{array}{l}\text { Table 1: It aims to identify the central idea of the relatives as to how the } \\
\text { treatment is offered by PCC II. } \mathrm{n}=20 \text {. Jundiaí. Brazil. }\end{array}$} \\
\hline Central Idea & Participants & Frequency \\
\hline Distraction & $3,6,10,11,12,16,19,20$ & 8 \\
\hline Assistance provided & $1,2,4,7$ & 4 \\
\hline Freedom & $14,15,16$ & 3 \\
\hline Adherence to treatment & 5,8 & 2 \\
\hline Insecurity & 9,17 & 2 \\
\hline Ineffective treatment & 13,16 & 2 \\
\hline
\end{tabular}

\section{Distraction}

"Yeah, very good, caring and supportive, distracting the patient and the family. He holds his head and distracts himself, forgets the problems he has with drinking and drugs."

The PCC offers varieties in therapeutic support such as individual and group visits, parties, therapeutic workshops, physical activities and leisure. These therapeutic varieties provide spaces for the production of subjectivities, where the construction of links, dialogues, interactions and encompasses beyond care with the disease as the interpersonal community in the community, aiming at social inclusion and redeeming citizenship [11].

\section{Assistance provided}

"It's very good, I like the treatment, it has a pleasant environment. The employees give more attention, words of comfort, they provide more assistance and he feels free"

The bonding and acceptance with the user by the mental health worker is fundamental and facilitates the construction of autonomy, through shared and stipulated accountability among individuals, favoring integrity in health care. The development of autonomy in users reduces suffering and improves quality of life [12].

\section{Freedom}

"Great, here he gets free, he does not get stuck, he can have a normal life, freedom in the days to come. It is excellent the interaction with other patients is well treated and taken care of. I think it's best for him because he's going home later"

The autonomy that PCC offers allows us to understand the vision compatible with the psychosocial model of treating mental health. The therapeutic activities offered consist of links, interactions, conversations, reciprocity and the acceptance of their choices, besides aggregating in the autonomy of the user, one obtains freedom to come and go [13].

\section{Adherence to Treatment}

"Great, getting the treatment is good, he can continue the treatment"

The PCC provides individual and group visits, free medications and therapeutic workshops. Adherence to treatment is indispensable since non-acceptance is related to relapses and persistence of psychotic symptoms [14].

\section{Insecurity}

"It helps a lot, but I do not like it coming, sometimes it's not enough for his and the others' safety, because I think I should share alcoholic with drugged with the other patients"

The PCC is the gateway to treatments for patients suffering from psychic disorders and also people who have psychoactive substance disorders [7]. According to Alves, Kessler and Ratto (2004) [15] about $50 \%$ of patients with psychiatric disorders are susceptible to develop problems related to alcohol / drug use. After the Psychiatric Reform, the PCC became the main treatment reference, so there is an interaction between patients with different diagnoses.

\section{Ineffective treatment}

"Treatment for him is slow, he is not in the middle of a lot of people, likes sports and not stay in the rooms, when he gets shaken"

Since the beginning of the Brazilian psychiatric reform, progress has been clear in the way of caring for and assisting patients with mental disorders, but there are still factors to be remedied.

The PCC is the only social reference and treatment for patients with mental disorders. There are still limitations in establishing the contractuality of patients with the community, making affectivity and social inclusion impossible [16].

Many patients do not adapt to the treatment offered by PCC, so they do not adhere to the treatment favoring psychiatric rehospitalization.

Patients who have experienced long-term hospitalizations are faced with difficulties in adapting and linking to PCC, causing the entire health team to negotiate with their families about therapeutic management [17].

PCC does not always offer activities in the therapeutic workshops in which it is in the patient's interest, which implies the participation of the therapeutic treatment and this shows the need for a review of the activities so that it can meet the patients' demands [13] (Table 2).

\begin{tabular}{|c|c|c|}
\hline \multicolumn{3}{|c|}{$\begin{array}{l}\text { Table 2: It aims to identify the central idea of relatives regarding hospi- } \\
\text { talization in psychiatric hospitals. n=20. Jundiaí. Brazil. }\end{array}$} \\
\hline Central Idea & Participants & Frequency \\
\hline Aggression & $3,4,7,8,11,15,16,17$ & 8 \\
\hline $\begin{array}{c}\text { Ineffective method of hospitaliza- } \\
\text { tion }\end{array}$ & $2,5,712,15,16,18$ & 7 \\
\hline Benefít of hospitalization & $1,6,10,13,19,20$ & 6 \\
\hline Family link & $2,14,9$ & 3 \\
\hline
\end{tabular}

\section{Aggression}

"Yes, if he is very aggressive and agitated, I think he has to be hospitalized because of the aggression, when he is in an outbreak, he breaks the whole house, he risks for him and for other people, no one can take it, , I have to call the police cause trouble because he gets dangerous, can kill himself and we are even afraid to die. As long as I can control it at home, I prefer it because there are more aggressive patients who should be separated from what they are not" 
In times of crisis, family members have difficulties in how to act correctly when episodes of agitation and verbal and physical aggression occur, causing physical and psychological exhaustion $[18,19]$.

The overload of family members of patients with mental disorders is related to the consequences that interfere with the family routine, such as financial, social and professional disorder, treatment assistance and suicide attempts.

Often the family member seeks a health service for not achieving a desired effect in the attempts to help the patient and with this can develop feelings such as guilt, exhaustion, fear and even despair1.

\section{Ineffective method of hospitalization}

"If I'm not aggressive and adhere well to the treatment I'm not in favour, because it does not solve. Internment leaves sicker, the person feels incapable, move, very strong treatment, without the will of the person, is not human. Better to take care of with respect, and treat him so that he has an interest in treating himself, I have to take advantage that it is the first time he wanted help, he said that alone he will not get, no more outbreaks, because I prefer him to stay in PCC, does not solve him getting hospitalized with drug addicts and drunk, so I prefer that he take medicine at home, if he interned it gets worse, better deal with support, talk and medication"

Through the Psychiatric Reform that revised the new treatment method, one of the major changes in care was to induce the family's participation in care along with the health service, making it easier for the user to stay in the care health unit for longer.

In the manicomial model the relatives were unable to obtain participation in the treatment, already today the relatives are considered as great allies in the treatment by the unit of care, since they are also responsible for the social reinsertion and in the care of the user [20].

\section{Benefit of hospitalization}

"Yes, for the sake of treatment, I am in favor if the condition worsens, if you have problems like outbreaks and develop another disease, provided it is temporary, that it has a humanized treatment to be able to treat until stabilizing and doing the correct treatment, as well I was less worried and I suffered less"

After the psychiatric reform, the relatives suffered from the therapeutic method offered by the support network, with which many relatives show favoritism for the institutionalization 16 . The preference for family members in treatments in hospital institutions is contrary to what the deinstitutionalized care model suggests, since the correct one would be the short stay in the hospital bed.

The family members often realize the indispensability of prolonged hospitalization, due to the difficulty they face in care and lack of preparation at times when the patient presents with seizures. Although they claim a preference for hospitalization, the family member himself can identify that there are no results in the treatment [21].
In addition to the difficulties encountered by relatives in caring for the patient, there is a stress related to the overload of functions, resulting in suffering, with the hospital being seen as a necessity for providing temporary relief [22].

\section{Family Link}

"No, because there they get stuck, away from me in conflicts, I prefer to take care of at home and I do not know how he would be treated, here I have no security I cannot stay together and he needs me, here I can follow and he goes to House"

The change in psychiatric care stimulates the family member in the participation of the care with the health services, in which it allows the stay for a longer period in his unit of care [18].

The approximation of the relatives in the therapeutic treatment is efficient and essential for the response of the users, being the familiar one becomes integral of the treatment [23].

It is important that family members receive instructions and support from the health services, since the home is an environment in which the patient can sustain the stability of the disease, maintaining a better quality of life [24].

\section{Conclusion}

Even with so many changes in the treatment of people with mental disorders after the Psychiatric Reform, most of the relatives are still in favor of the hospitalization of their relatives, thus claiming central ideas such as: aggression, benefit of hospitalization, ineffective treatment and insecurity. that hospitalization is an effective method for treatment.

The family members who are against hospitalization are represented by the following central ideas: distraction, care provided, freedom, adherence to treatment, ineffective method of hospitalization and family bonding, thus having the perception that PCC is the best treatment method.

\section{Acknowledgements}

None.

\section{Conflict of interest}

The author declares that there is no conflict of interest.

\section{References}

1. Cultural Center Ministry of Health (2018) Brazilian psychiatric reform and mental health politics.

2. State Secretary for Health (2003) Who was Phillippe Pinel.

3. Federal University of Rio Grande do Sul (2018) Who was Franco Basaglia?

4. Santin G, Klafke TE (2011) Family and mental health care. Barbaroi, Santa Cruz do Sul, Brazil, p. 34.

5. Borges CF, Baptista TWF (2008) The care model in mental health in Brazil: the trajectory of political construction from 1990 to 2004. Oswaldo Cruz Foundation, National School of Public Health Sergio Arouca, Rio de Janeiro, Brazil, p. 24(2).

6. Soares RD, Villela JC, Borba LO, Brusamarello T, Maftum MA (2011) The role of the nursing team in the psychosocial care center. Anna Nery School, Rio de Janeiro, Brazil p. 15(1). 
7. (2018) Mental Health in the SUS: The Psychosocial Care Centers 2004.

8. Bielemann VLM, Kantorski LP, Borges LR, Chiavagatti FG, Willrich JQ et al. (2009) The Insertion of the Family in Psychosocial Care Centers under the Perspective of its Social Actors. Texto context-enferm, Florianópolis, Brazil, 18(1).

9. Lefèvre F, Lefèvre AMC, Teixeira JJV (2000) The Discourse of the Collective Subject. São Paulo, Brazil.

10. Trivios ANS (1992) Introduction to social science research. São Paulo, Brazil.

11. Kantorski LP, Coimbra VCC, Damarco DA, Eslabão AD, Nunes CK, et al (2011) The importance of therapeutic support activities for care in a Care Center. Nursing and Health Magazine, Pelotas (RS), Brazil, 1(1): 4-13.

12. Jorge MSB, Pinto DM, Quinderé PHD, Pinto AGA, Soussa FS, et al. (2011) Mental Health Promotion - Care Technologies: bonding, acceptance, responsibility and autonomy. Science and Collective Health, Rio de Janeiro, Brazil, 16(7).

13. Pinho LB, Kantorski LP, Wetzel C, Schwartz E, Lange C, et al. (2013) Therapeutic activities: understanding of relatives and professionals of a psychosocial care center. Anna Nery School, Rio de Janeiro, Brazil, 17(3).

14. Zago AC, Tomasi E, Demori CC (2015) Adherence to the drug treatment of users of psychosocial care centers with mood disorders and schizophrenia. Ribeirão Preto: Electronic Journal of Mental Health, Alcohol Drug 11(4): 224-233.

15. Kantorski LP, Jardim VMR, Oliveira MM, Alves FP, Silveira KL, et al. (2014) Alcohol consumption in mental health services in Rio Grande do Sul. Occupational Therapy Notebook. UFSCar, São Carlos 22 (Special Supplement): 103-109.

16. Costa AA, Trevisan ER (2012) Psychosocial changes in the family context after the de-hospitalization of the subject with mental disorders. Health in Debate, Rio de Janeiro, Brazil, 36(95): 606-614.

17. Pereira AR, Joazeiro G (2015) Perception of hospitalization in a psychiatric hospital by patients diagnosed with schizophrenia. The World of Health, São Paulo, Brazil, 39(4): 476-483.

18. Campana MC, Soares MH (2015) Relatives of people with schizophrenia: feelings and attitudes towards aggressive behavior. Curitiba (PR) Cogitare Enferm 20(2)

19. Mielke FB, Kohlrausch E, Olschowsky A, Schneider JF (2010) The inclusion of the family in psychosocial care: a reflection. Electronic Nursing Journal 12(4): 761-765.

20. Duarte MLC, Kantorski LP (2011) Evaluation of care given to relatives in a psychosocial care center. Brazilian Journal of Nursing 64(1).

21. Bessa JB, Waidman MAP (2013) Family of the person with Mental Disorder and their Needs in Psychiatric Care. Text \& Context Nursing 22(1): 61-70.

22. Randemark NFR, Jorge MSB, Queiroz MVO (2004) Psychiatric reform in the eyes of families. Text Context Nursing 13(4): 543-550.

23. Martins PPS, Lorenzi CG (2016) Family Participation in Mental Health Treatment as a Practice in the Daily Life of the Service. Psychology, Theory and Research, Brasília, 32(4).

24. Cardoso L, Galera SAF (2011) Mental health care today. Magazine USP School of Nursing 45(3): 687-691. 